\title{
Dural Arteriovenous Fistula Associated With a Vestibular Tumor: An Unusual Case and Review of the Literature
}

Michael E. Kritikos ${ }^{1}$, Martin Oselkin ${ }^{2}$, Nikhil Sharma ${ }^{1}$, Pallavi P. Gopal ${ }^{3}$, Douglas C. Bigelow ${ }^{4}$, Sean Grady ${ }^{1}$, Robert W. Hurst ${ }^{5}$, Bryan A. Pukenas ${ }^{5}$, Omar Choudhri ${ }^{6}$, David Kung ${ }^{1}$

1. Neurosurgery, Hospital of the University of Pennsylvania, Philadelphia, USA 2. Neuroradiology, Hospital of the University of Pennsylvania, Philadelphia, USA 3. Pathology, Hospital of the University of Pennsylvania, Philadelphia, USA 4. Otorhinolaryngology, Hospital of the University of Pennsylvania, Philadelphia, USA 5. Radiology, Hospital of the University of Pennsylvania, Philadelphia, USA 6. Neurosurgery, Hospital of University of the Pennsylvania, Philadelphia, USA

Corresponding author: Michael E. Kritikos, michaeleliaskritikos@gmail.com

\begin{abstract}
Intracranial dural arteriovenous fistulae (DAVF) are rare vascular malformations. They are generally considered to be acquired lesions, often attributed to dural sinus thrombosis and intracranial venous hypertension. The authors encountered a case of DAVF associated with an octreotide-positive vestibular schwannoma. A 46-year-old female had symptoms of right ear congestion accompanied by pulsatile tinnitus and mild hearing loss. Magnetic resonance imaging (MRI) identified a lobulated mass centered at the cerebellopontine angle. Preoperatively, on cerebral angiography, there was an incidental discovery of a DAVF in the right posterior fossa. The decision was made to proceed with resection of the tumor in a staged fashion. Her latest follow-up MRI showed no evidence of recurrent tumor. This is the second reported case of DAVF associated with an intracranial schwannoma. Findings are discussed along with a thorough review of the literature. This case, combined with the data from the literature review, led us to believe that tumorrelated angiogenesis might contribute to DAVF formation.
\end{abstract}

Received 06/05/2018 Review began 06/11/2018 Review ended 06/25/2018 Published 06/27/2018

๑) Copyright 2018 Kritikos et al. This is an open access article distributed under the terms of the Creative Commons Attribution License CC-BY 3.0., which permits unrestricted use, distribution, and reproduction in any medium, provided the original author and source are credited.
Categories: Neurosurgery

Keywords: dural arteriovenous fistula, vestibular schwannoma, octreotide scintigraphy, somatostatin receptor, angiogenesis, intracranial tumor

\section{Introduction}

Intracranial dural arteriovenous fistulae (DAVF) are abnormal direct shunts between dural arteries and dural venous sinuses, meningeal veins or cortical veins. They are located within or near the wall of the dural sinus and account for $10 \%-15 \%$ of all intracranial arteriovenous malformations [1]. DAVF primarily occur in adult patients and are most commonly located in the transverse-sigmoid sinus region followed by the cavernous sinus; however, any intracranial venous sinus may be involved [2]. They are widely considered to be acquired lesions. Their acquired nature is further supported by their association with dural sinus thrombosis, head trauma, intracranial or spinal tumors [3-4], localized infection, previous neurosurgical procedures [1-2], and hypercoagulation states [1].

We encountered a rare case of a transverse-sigmoid sinus DAVF associated with the presence of a vestibular schwannoma, which occluded the right transverse and sigmoid sinuses. The pre-operative diagnosis of this lesion was confounded by the fact that the tumor was positive on octreotide nuclear scintigraphy.

\section{Case Presentation}

A 46-year-old female had symptoms of right ear congestion accompanied by pulsatile tinnitus and mild hearing loss. Neurological examination revealed weakness of cranial nerves X and XII. Magnetic resonance imaging (MRI) identified a $4.2 \times 4.7 \times 4.1 \mathrm{~cm}$ lobulated mass centered the cerebellopontine angle that was hypointense on T1-weighted, heterogeneous on T2-weighted, and avidly enhancing on post-contrast images (Figure $1 A$ ). No significant component was noted within the internal auditory canal. An Octreoscan was performed, which showed intense increased tracer uptake in the mass centered in the region of the right jugular foramen, thereby supporting the suspected diagnosis of paraganglioma (Figure $1 B$ ). 


\section{Cureus}

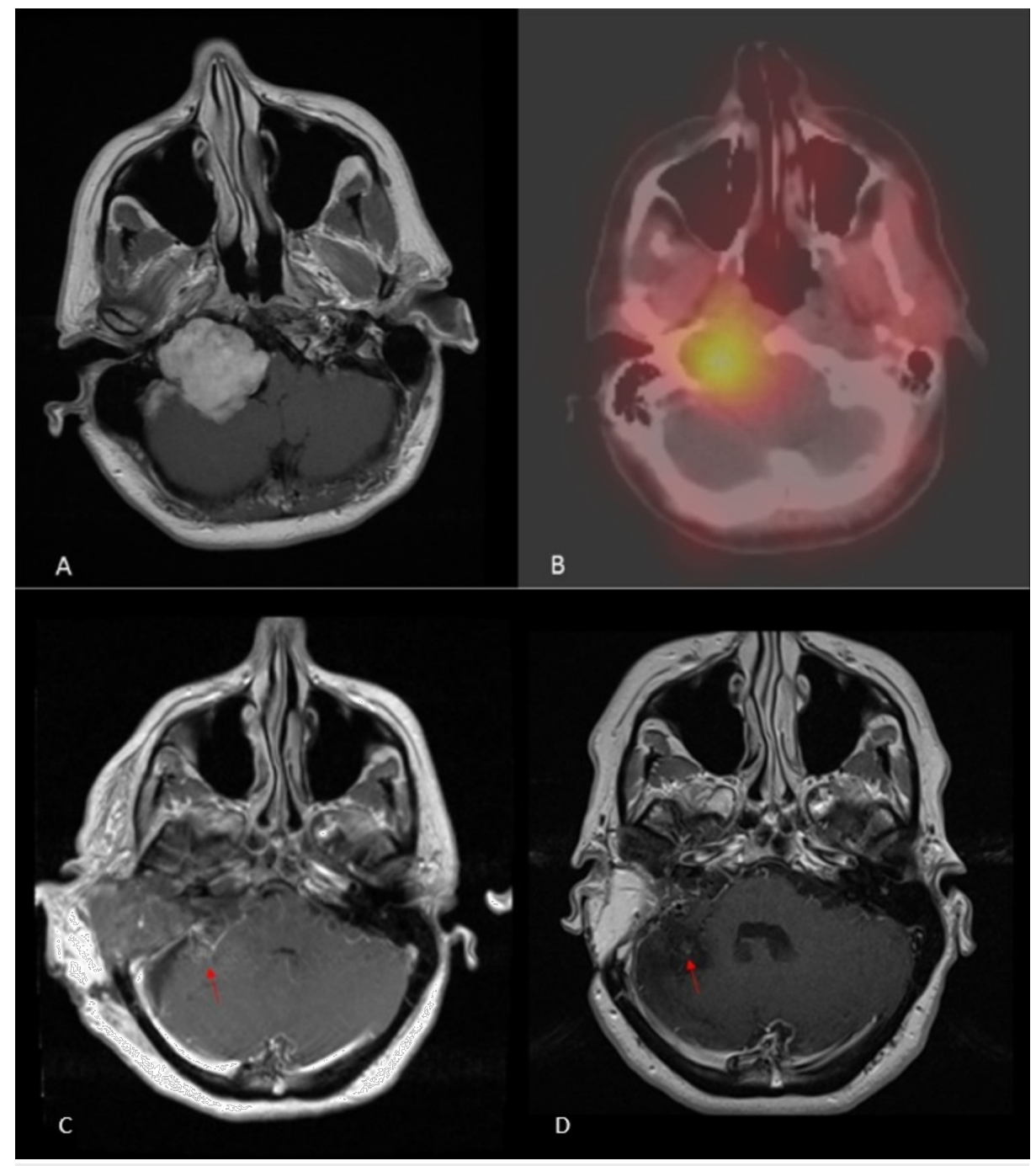

\section{FIGURE 1: Magnetic resonance imaging and Octreoscan}

T1-weighted post-contrast MRI (magnetic resonance imaging) (A) demonstrates the avidly enhancing large right skull base mass centered at the jugular foramen, involving the right carotid space inferiorly and the right hypoglossal canal. 24-hour In-111 Pentetreotide SPECT-CT (single-photon emission computed tomography) fused images (B) demonstrates intense uptake in the mass.

Initial post-operative T1-weighted post-contrast MRI (C) demonstrates expected post-surgical changes related to the skull base mass resection with no residual enhancing tumor. Follow-up MRI (D) four years later demonstrates stable post-operative changes with no residual mass. Tiny focus of enhancement beneath the tentorium likely reflected residual DAVF (dural arteriovenous fistula) (red arrow).

Digital subtraction angiography (DSA) demonstrated a surprising lack of vascularity associated with the tumor. However, there was an incidental discovery of a Cognard IIa+b dural arteriovenous fistula in the right posterior fossa associated with an occluded right sigmoid sinus (Figure $2 A-2 D$ ). 


\section{Cureus}
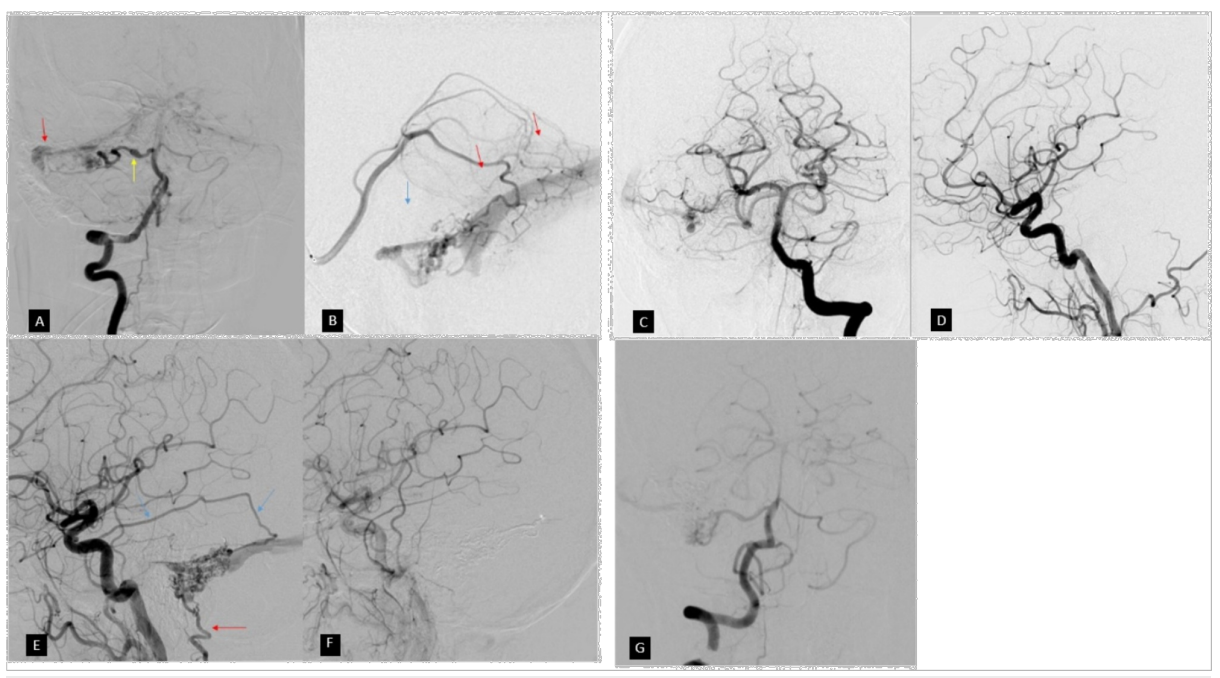

FIGURE 2: Digital subtraction angiography

Initial cerebral angiogram planned for pre-operative embolization of the suspected paraganglioma did not demonstrate significant tumor vascularity. Incidentally, a dural arteriovenous fistula was seen predominantly supplied by the right AICA (anterior inferior cerebellar artery) on right vertebral artery injection (A). The right AICA is irregular with mild fusiform dilatation (yellow arrow). Microcatheter injection in the right SCA (superior cerebellar artery) (B) demonstrates a smaller component of the fistula not well seen on the right vertebral artery injection due to rapid shunting into the AICA. Additional very small arterial feeders were identified from branches of the right MMA (middle meningeal artery). There was cortical venous drainage (blue arrow) along the right cerebellar hemisphere to the right transverse sinus (red arrow), which then drained in retrograde fashion across the torcula and into the left transverse and sigmoid sinuses.

Following embolization using Onyx in the right AICA and SCA DAVF (dural arteriovenous fistula) feeders, left vertebral artery DSA (digital subtraction angiogram) injection (C) demonstrates significant reduction in arteriovenous shunting. Again, there was no appreciable vascularity in the skull base mass. Right CCA (common carotid artery) injection (D) following embolization did not reveal additional feeders to the DAVF or mass.

Follow-up DSA four years after initial embolization. Right CCA injection (E) reveals recurrence of the DAVF with new prominent feeders from the right MMA (blue arrow) and occipital (red arrow) arteries. Following embolization using Onyx in the right MMA feeder, right CCA injection in the late arterial phase (F) demonstrates resolution in shunting through the right CCA.

(G) Right vertebral artery injection on the most recent DSA following MMA embolization demonstrates mild residual shunting similar to prior. There has been interval resolution of the dysplastic proximal right AICA.

Due to the extensive volume of tumor, the patient underwent a staged surgical resection. The first surgery included a modified radical right neck dissection, right superficial parotidectomy with facial nerve dissection, as well as the initial approach to the tumor and partial extradural resection. One week later, the patient underwent the second stage surgery where the tumor was radically resected using a right transcochlear approach. The right sigmoid sinus was ligated. The facial nerve was mobilized and transposed. Postoperative MRI confirmed complete resection of the tumor (Figure 1C). Histological analysis of samples from both surgeries confirmed the tumor not to be a paraganglioma, but instead a schwannoma (Figure 3). 


\section{Cureus}

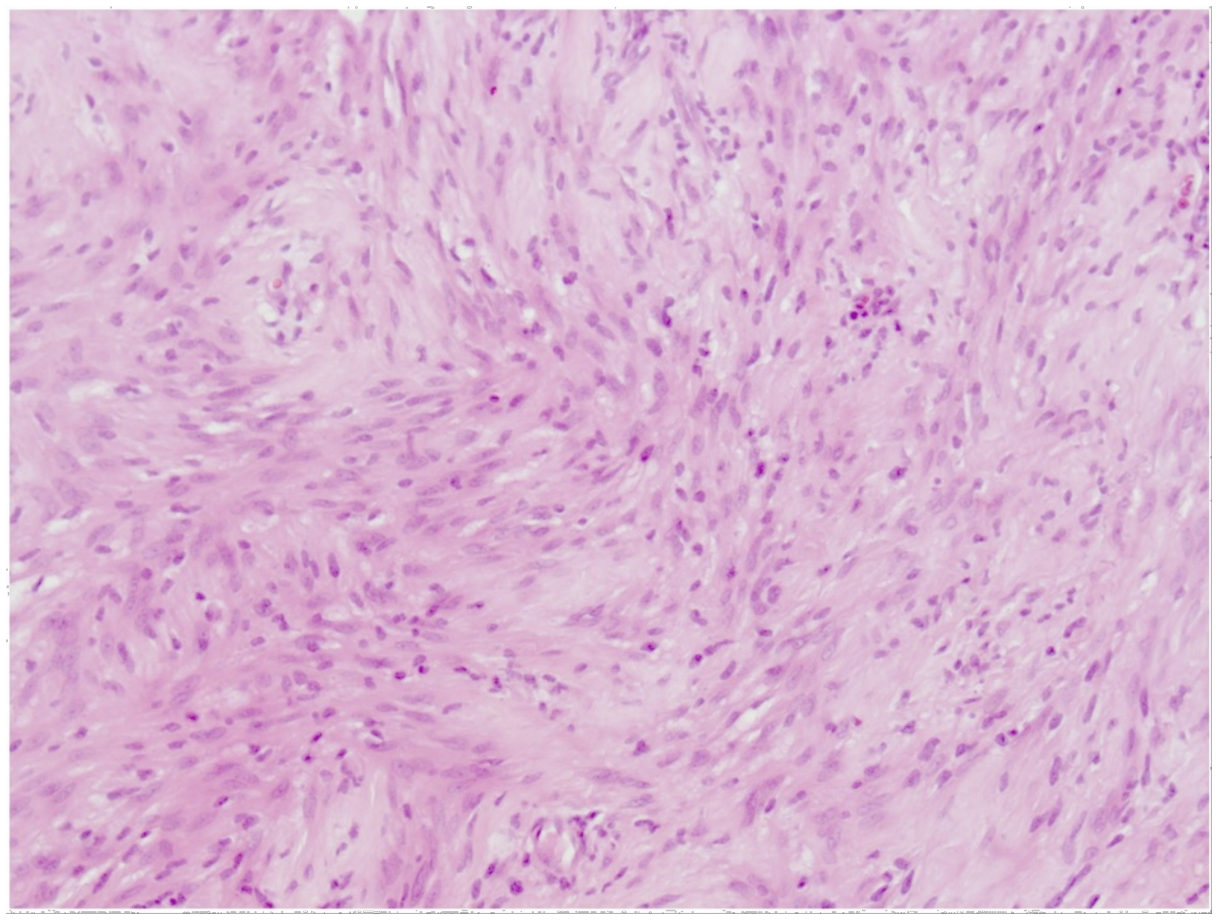

\section{FIGURE 3: Photomicrograph}

Hematoxylin and eosin stained sections showed a biphasic tumor composed of spindle-shaped cells arranged in compact interlacing fascicles with areas of denser cellularity alternating with more loosely arranged cells, consistent with a schwannoma. Tumor cells were immune-positive for $\mathrm{S} 100$ (not shown). Areas of collagen deposition, ancient-type changes and lymphocytic perivascular infiltrates were also present (200x magnification).

She had a long recovery from the surgery due to the lower cranial nerve palsies but has shown gradual improvement. Her latest follow-up MRI (48 months from surgery) (Figure 1D) showed no evidence of recurrent tumor; however, there was some residual posterior fossa DAVF. At that time, she also reported bothersome pulsatile tinnitus that she perceives on the right despite a complete hearing loss on the right side. DSA revealed new large feeders from the right middle meningeal artery (MMA) and occipital arteries into the residual DAVF (figure 2E), which were not present on initial presentation (Figure 2D). The DAVF was embolized utilizing Onyx in the right MMA. Final right common carotid artery (CCA) angiogram demonstrated resolution in arteriovenous shunting (Figure 2F). Vertebral artery injection after embolization demonstrated minimal residual shunting via the right anterior inferior cerebellar artery (AICA) (Figure 2G). A further intervention was declined by the patient and angiographic follow-up in one year has been scheduled.

\section{Discussion}

In our patient, we encountered a transverse-sigmoid sinus DAVF associated with a schwannoma of the right skull base. Although angiography was not available prior to diagnosis of the large skull base mass, one could hypothesize that the schwannoma led to the venous sinus obstruction, and subsequently the formation of the DAVF. DAVF formation attributed to a tumor has been described, but it is rare. A detailed PubMed query was performed, which identified 26 previously reported cases (Table 1) [3-17]. Analysis of the previously reported cases exhibited a slight female predominance (61.5\%) and a mean age of 60.26 years (range 25-78). This is only the second case associated with an intracranial schwannoma. In the vast majority of cases (78\%), the tumor was a meningioma. Although there are exceptions, most cases of DAVF associated with tumor are also associated with sinus obstruction, underlining the importance of venous outflow obstruction in DAVF pathophysiology. Specifically, the most common location of occlusion was the sigmoid sinus, which was occluded in $38.5 \%$ of cases. Interestingly, $23 \%$ of cases were not related to sinus occlusion. The most common location for a DAVF associated with a tumor was the transverse-sigmoid sinus (48\% of cases). Some investigators hypothesize that meningiomas are the most likely tumor type to be associated with DAVF due to their highly vascular nature, which in turn accentuates venous hypertension, especially when the sinus is occluded [14].

\begin{tabular}{|c|c|c|c|c|c|c|}
\hline $\begin{array}{l}\text { Author } \\
\text { (year) }\end{array}$ & Age/Sex & Tumor/Location & DAVF & $\begin{array}{l}\text { Sinus } \\
\text { Occlusion }\end{array}$ & Treatment of DAVF & Follow-up \\
\hline
\end{tabular}




\section{Cureus}

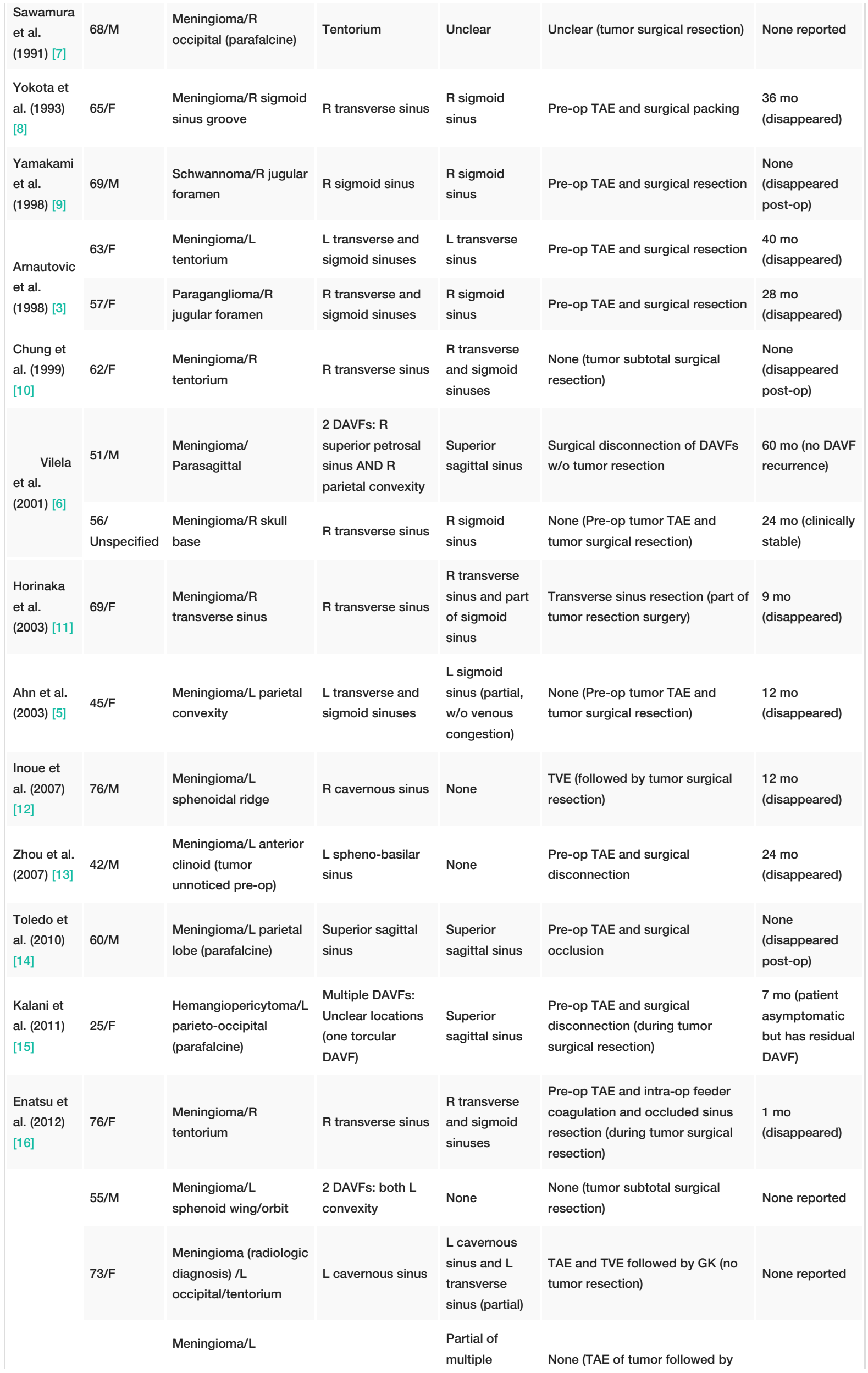




\section{Cureus}

\begin{tabular}{|c|c|c|c|c|c|c|}
\hline & $69 / \mathrm{M}$ & $\begin{array}{l}\text { convexity (fronto- } \\
\text { temporal) }\end{array}$ & $R$ transverse sinus & $\begin{array}{l}\text { unspecified } \\
\text { sinuses }\end{array}$ & tumor surgical resection) & None reported \\
\hline & 41/F & $\begin{array}{l}\text { Meningioma/R lateral } \\
\text { ventricle-trigone }\end{array}$ & L convexity & None & $\begin{array}{l}\text { TAE (followed by tumor surgical } \\
\text { resection) }\end{array}$ & None reported \\
\hline \multirow[t]{6}{*}{$\begin{array}{l}\text { Vellimana } \\
\text { et al. } \\
\text { (2014) [17] }\end{array}$} & $54 / F$ & $\begin{array}{l}\text { Meningioma (radiologic } \\
\text { diagnosis)/R petrous } \\
\text { apex }\end{array}$ & $\begin{array}{l}\mathrm{L} \text { transverse and } \\
\text { sigmoid sinuses }\end{array}$ & $\begin{array}{l}R \text { cavernous } \\
\text { sinus }\end{array}$ & TAE (followed by GK for tumor) & None reported \\
\hline & 57/M & $\begin{array}{l}\text { Meningioma (radiologic } \\
\text { diagnosis)/L parasellar }\end{array}$ & L convexity & $\begin{array}{l}\mathrm{L} \text { cavernous } \\
\text { sinus }\end{array}$ & $\begin{array}{l}\text { None (fractionated radiotherapy } \\
\text { for tumor) }\end{array}$ & None reported \\
\hline & 78/F & $\begin{array}{l}\text { Meningioma (radiologic } \\
\text { diagnosis)/L convexity } \\
\text { (frontal) }\end{array}$ & L cavernous sinus & $\begin{array}{l}\text { L cavernous } \\
\text { sinus }\end{array}$ & TAE (no tumor resection) & None reported \\
\hline & $67 / F$ & $\begin{array}{l}\text { Phosphaturic } \\
\text { mesenchymal tumor/L } \\
\text { anterior cranial fossa }\end{array}$ & Lateral tentorial & None & $\begin{array}{l}\text { Surgical resection (following failed } \\
\text { TAE) }\end{array}$ & None reported \\
\hline & 72/M & $\begin{array}{l}\text { Meningioma/ Planum } \\
\text { sphenoidale }\end{array}$ & Ethmoidal sinus & None & Surgery (during tumor resection) & None reported \\
\hline & $61 / F$ & $\begin{array}{l}\text { Meningioma/ Olfactory } \\
\text { groove }\end{array}$ & $\begin{array}{l}\mathrm{R} \text { transverse and } \\
\text { sigmoid sinuses }\end{array}$ & $\begin{array}{l}\text { Superior } \\
\text { sagittal sinus }\end{array}$ & GK and TAE & None reported \\
\hline $\begin{array}{l}\text { Hatanaka } \\
\text { et al. } \\
\text { (2015) } 41\end{array}$ & 70/F & $\begin{array}{l}\text { Schwannoma/ Spinal } \\
\text { (C2 level) }\end{array}$ & $\begin{array}{l}\mathrm{R} \text { transverse and } \\
\text { sigmoid sinuses }\end{array}$ & $\begin{array}{l}R \text { sigmoid } \\
\text { sinus }\end{array}$ & $\begin{array}{l}\text { TAE and TVE (followed by tumor } \\
\text { surgical resection). GK after DAVF } \\
\text { recurrence } 6 \text { mo post-intervention }\end{array}$ & $\begin{array}{l}33 \text { mo } \\
\text { (disappeared) }\end{array}$ \\
\hline
\end{tabular}

DAVF: dural arteriovenous fistula; TAE: transarterial embolization; TVE: transvenous embolization; GK: gamma knife radiosurgery

TABLE 1: Reported cases of dural arteriovenous fistulae associated with tumor in adult patients

Another unique characteristic in our case was the positive 111In-octreotide scintigraphy (Octreoscan), which is used to evaluate the presence of somatostatin receptors in intracranial tumors in vivo. Expression of somatostatin receptors has been linked with increased angiogenic activity in meningiomas and other neoplasias [18]. This is only the second reported case of an intracranial schwannoma with positive octreotide scintigraphy [19]. Past studies have shown that somatostatin receptors are expressed in most meningiomas, paragangliomas and hemangiopericytomas, but not in schwannomas, with some investigators using octreotide scintigraphy for the differential diagnosis of meningioma versus schwannoma [19-20]. Our case further supports the conclusion by Dupuch et al. that no investigation is able to establish a definitive preoperative differential diagnosis between schwannoma and meningioma [19]. Taking into consideration the case we encountered, we hypothesize that aberrant angiogenesis through somatostatin receptor pathways may play a role in the pathogenesis of DAVF associated with intracranial tumors. Even though there is currently no evidence showing a direct connection between somatostatin pathways and DAVF formation, studies have shown that the presence of somatostatin receptors correlates with aberrant angiogenesis in various tumor settings [18]. Our hypothesis aims at opening new avenues of investigation that will help in better understanding DAVF pathophysiology.

\section{Conclusions}

In summary, we present an unusual case of DAVF associated with an octreotide positive vestibular schwannoma. This case demonstrates that lesions in the cerebellopontine angle could affect local vasculature, possibly by both causing local venous hypertension and somatostatin receptor-related angiogenesis, to the extent it may lead to a DAVF formation.

\section{Additional Information \\ Disclosures}

Human subjects: Consent was obtained by all participants in this study. Conflicts of interest: In compliance with the ICMJE uniform disclosure form, all authors declare the following: Payment/services info: All authors have declared that no financial support was received from any organization for the submitted work. Financial relationships: All authors have declared that they have no financial relationships at present or within the previous three years with any organizations that might have an interest in the submitted work. Other relationships: All authors have declared that there are no other 


\section{References}

1. Gandhi D, Chen J, Pearl M, Huang J, Gemmete JJ, Kathuria S: Intracranial dural arteriovenous fistulas: classification, imaging findings, and treatment. AJNR Am J Neuroradiol. 2012, 33:1007-1013. 10.3174/ajnr.A2798

2. Cognard C, Gobin YP, Pierot L, et al.: Cerebral dural arteriovenous fistulas: clinical and angiographic correlation with a revised classification of venous drainage. Radiology. 1995, 194:671-680. 10.1148/radiology.194.3.7862961

3. Arnautovic KI, Al-Mefty O, Angtuaco E, Phares LJ: Dural arteriovenous malformations of the transverse/sigmoid sinus acquired from dominant sinus occlusion by a tumor: report of two cases. Neurosurgery. 1998, 42:383-388. 10.1097/00006123-199802000-00112

4. Hatanaka R, Takai K, Iijima A, Taniguchi M: Intracranial dural arteriovenous fistula associated with a spinal tumor: a case report. Acta Neurochir (Wien). 2015, 157:1825-1827. 10.1007/s00701-015-2533-2

5. Ahn JY, Lee BH, Cho YJ, Joo JY, Lee KS: Dural arteriovenous fistula associated with meningioma: spontaneous disappearance after tumor removal. Neurol Med Chir (Tokyo). 2003, 43:308-311. 10.2176/nmc.43.308

6. Vilela P, Willinsky R, terBrugge K: Dural arteriovenous fistula associated with neoplastic dural sinus thrombosis: two cases. Neuroradiology. 2001, 43:816-820. 10.1007/s002340100570

7. Sawamura Y, Janzer RC, Fankhauser H, de Tribolet N: Arteriovenous malformation in meningothelial meningioma: case report. Neurosurgery. 1991, 29:109-112. 10.1227/00006123-199107000-00019

8. Yokota M, Tani E, Maeda Y, Yamaura I: Meningioma in sigmoid sinus groove associated with dural arteriovenous malformation: case report. Neurosurgery. 1993, 33:316-319. 10.1227/00006123-19930800000022

9. Yamakami I, Ono J, Yamaura A: Sigmoid sinus dural arteriovenous malformation resulting from jugular foramen schwannoma--case report. Neurol Med Chir (Tokyo). 1998, 38:43-46. 10.2176/nmc.38.43

10. Chung YG, Lee KC, Lee HK, Lee NJ: Tentorial meningioma encroaching the transverse sinuses and sigmoid sinus junction area associated with dural arteriovenous fistulous malformation: a case report. J Korean Med Sci. 1999, 14:465-468. 10.3346/jkms.1999.14.4.465

11. Horinaka N, Nonaka Y, Nakayama T, Mori K, Wada R, Maeda M: Dural arteriovenous fistula of the transverse sinus with concomitant ipsilateral meningioma. Acta Neurochir (Wien). 2003, 145:501-504. 10.1007/s00701-003-0030-5

12. Inoue T, Nishimura S, Hayashi N, Numagami Y, Tomita T, Nishijima M: Cavernous sinus dural arteriovenous fistula associated with the development of sphenoidal ridge meningioma--case report. Neurol Med Chir (Tokyo). 2007, 47:317-321. 10.2176/nmc.47.317

13. Zhou LF, Chen L, Song DL, Gu YX, Leng B: Dural arteriovenous fistula of the sphenobasilar sinus with concomitant meningioma: case report and review of the literature. Neurosurg Rev. 2007, 30:269-274. 10.1007/s10143-007-0071-y

14. Toledo MM, Wilson TJ, Dashti S, McDougall CG, Spetzler RF: Dural arteriovenous fistula associated with superior sagittal sinus occlusion secondary to invasion by a parafalcine meningioma: case report. Neurosurgery. 2010, 67:205-207. 10.1227/01.NEU.0000370089.94032.4F

15. Kalani MY, Martirosyan NL, Eschbacher JM, Nakaji P, Albuquerque FC, Spetzler RF: Large hemangiopericytoma associated with arteriovenous malformations and dural arteriovenous fistulae. World Neurosurg. 2011, 76:597-510. 10.1016/j.wneu.2011.05.023

16. Enatsu R, Asahi M, Matsumoto M, Hirai O: Meningioma-related dural arteriovenous fistula fed via a vascular tumor bed: a case report and literature review. Clin Neurol Neurosurg. 2012, 114:1010-1013. 10.1016/j.clineuro.2012.01.017

17. Vellimana AK, Daniels DJ, Shah MN, Zipfel GJ, Lanzino G: Dural arteriovenous fistulas associated with benign meningeal tumors. Acta Neurochir (Wien). 2014, 156:535-544. 10.1007/s00701-013-1946-Z

18. Barresi V, Alafaci C, Salpietro F, Tuccari G: Sstr2A immunohistochemical expression in human meningiomas: is there a correlation with the histological grade, proliferation or microvessel density?. Oncol Rep. 2008, 20:485-492. 10.3892/or_00000032

19. Dupuch V, Pastourel R, Gilain L, Mom T: A case of facial nerve schwannoma with positive octreotide scintigraphy [Article in English, French]. Eur Ann Otorhinolaryngol Head Neck Dis. 2015, 132:113-114. 10.1016/j.anorl.2014.06.004

20. Schmidt M, Scheidhauer K, Luyken C, et al.: Somatostatin receptor imaging in intracranial tumours. Eur J Nucl Med. 1998, 25:675-686. 10.1007/s002590050269 